\title{
Factors that Influenced the Quality Inspection on the Production Line in Manufacturing Industry
}

\author{
Yunos Ngadiman ${ }^{1}$, Burairah Hussin ${ }^{2}$, Abdul Talib Bon ${ }^{3}$ and Nor Aziati Abdul Hamid ${ }^{1}$ \\ ${ }^{1}$ Faculty of Technology Management and Business, Universiti Tun Hussein Onn Malaysia, Parit Raja, Batu Pahat, Johor \\ ${ }^{2}$ Faculty of Information Technology and Communacation, Universiti Teknikal Malaysia Melaka, Durian Tunggal, Melaka \\ ${ }^{3}$ Faculty of Technology Management and Business, Universiti Tun Hussein Onn Malaysia, Parit Raja, Batu Pahat, Johor
}

\begin{abstract}
The quality of a product is the main concern for customers. Hence, the objectives of this research are to determine factor that affect the inline quality inspection and improvement solutions of the quality inspection standard in the production process. Meanwhile, the scopes of the research are studying of all the factors that influence inline quality inspection and techniques to improve quality inspection standard. Hence, interviews had been carried out towards the respondents who work under the Quality Assurance Department and in charge of inline quality inspection. Through analyzing the chosen products which were cot sheet and latex cap, it can be said that worker, material, and machine are the most common factors that cause defects on the products. Therefore, the result of this research shows that the worker's training, maintenance and checking procedure of incoming raw materials are the main influence factors to overcome the problems occurred.
\end{abstract}

\section{Introduction}

This study is to determination of the factors that influence in-process quality inspection standard for manufacturer of water sports and leisure swimming products at Rubber Leisure Private Limited. Inspection is the most common method attaining standardization, uniformity and quality of workmanship. Inspection activity play a crucial role to ensure the products meet the specific requirements and produce good quality of products to fulfill the customer needs and wants. There are three types of quality inspection which are incoming inspection, in-process inspection and final inspection. This case study focus only in-process quality inspection in the manufacturing industry.

The inspection methods that used by this company are sampling inspection and $100 \%$ inspection. Sampling inspection is conduct on the semi-finished product or work-in-process products. Meanwhile, 100\% inspection is conduct for all the products in the company and ended with segregate out the good products and nonconformance products.

The factors that influence in-process quality inspection are being analyzed for its causes and effects. The research is done for determine the improvement solutions for quality inspection standard by conducting more literature review to search for journals, books and any other source on quality inspection method. The research methodology continues by doing the case study of the company.

\section{Problem statement}

Rubber Leisure Pte. Ltd. had implemented sampling inspection and $100 \%$ inspection to ensure the products meet the specific requirements and identify problems as they arise during the production process, thus allowing corrective action to be taken at an early stage.

Sampling inspection [1] either for the grading or for checking the correctness of the grading should be done most accurately, because unless the sample is truly representative of the entire lot, correct grading cannot be done. The general characteristics of the commodity should be preliminarily inspected before drawing samples from the lot. Meanwhile, 100\% inspection determining whether a commodity in a particular lot complies with the standard specifications applicable to it or any other specification stipulated in the trade contract.

In Rubber Leisure Pte. Ltd., there are actually some problems occur and affect the end product's quality. Normally, this is due to the mistakes that made on the inprocess quality inspection [2]. One of the problem is the product looks similar between bad product and good product, it can't be differentiate by the eye visual inspection. Then, the customer loyalty may drop. There are several factors that may influence the in-process quality inspection in this company. Therefore, improvement solutions will be proposed to the company 
and may implement a proper management procedures in monitoring defective products [3].

\section{Data analysis}

According to Table 1, it showed the quality policy, objectives and target for the year 2014 and 2015. Based on the major products reject rate, latex cap and the cot sheet both products need to achieve below $1.0 \%$ of reject rate. If exceed $1.0 \%$ of reject rate, the quality assurance's officer will act to necessary action .

Table 1. Quality policy, objective and target

\begin{tabular}{|l|l|}
\hline \multicolumn{1}{|c|}{ Quality Objectives } & \multicolumn{1}{c|}{ Target } \\
\hline Customer complaint & $<0.5 \%$ \\
\hline ETD fulfillment & $>99 \%$ \\
\hline Customer satisfaction index & $=100 \%$ \\
\hline Number of new products & $>4$ products \\
\hline $\begin{array}{l}\text { Fulfillment of training pelan } \\
\text { - Latex cap/Latex stock/Cot Sheet/ Hand } \\
\text { Built Cap/ } \\
\begin{array}{l}\text { Silicone Cap/Baby Bath Mat } \\
\text { Place Mat/Baby Bib }\end{array}\end{array}$ & Below $1.0 \%$ \\
\hline
\end{tabular}

\section{Discussion}

This research discussed regarding the factors that influence quality inspection during production process in Rubber Leisure Pte. Ltd.. There are also search to identify the improvement solutions of the quality inspection standard in the the production process [5].

\subsection{Implication of men factor}

Base on the research's result, training is an important criteria to ensure that the workers have sufficient knowledge and skills to complete tasks during the production process [6]. According to the interviews transcript for this company, when there is new worker start working, the company will apply on job training toward them. Throughout the time, the employer will provide them a lot in-house training. The benefits of doing on job training is it can provides a variety of job experiences for the workers [7]. Besides, it can help the worker to understand all the processes activities in manufacturing rubber products [8].

Besides, there is a method that triggered worker's performance which is applying job appraisal [9]. It is used by this company to ensure high performance of employee [10]. This actually quite effective way to attract it's workers intention and motivate them to work effectively. An appraisal may provides an insight into the work being done and the workers who are doing it.

In addition, the surrounding or environment in the workplace also plays a crucial role to ensure the workers can complete their tasks safely and comfortably [11]. Physical environmental issues like distracting noise, bad lightning, rubber smell, uneven temperature, cleanliness and others factors may influence the influence feeling and emotion of a worker to carry out work [11]. Hence, it might indirectly affect men's performance during production process.

\subsection{Implication of machine factor}

Machine factor is also plays an important role to ensure quality products being produce and complete task in scheduled time. Normally, the machine problems are due to the downtime or machine spoilt and cannot run [12]. Even if the machine can run, but the product quality will be affected.

Hence, preventive maintenance had applied by this company in order to overcome the problem. It is because preventive maintenance [13] can provide systematic inspection, detection and correction of incipient failures either before problems occur or before problems develop into major defects. If there is no application of proactive action, it might cause higher downtime and lower productivity rate in the production process. Besides, it is necessary to conduct routine inspection before machine spoilt like servicing the machine within the time schedule [14].

\subsection{Implication of material factor}

Material is the main concern of producing rubber products [15]. Hence, the incoming quality control (IQC) plays an important role to check the incoming raw material before being processing to end products [16].

There are several reasons that may affect the rubber product's quality due to the material in this company. Firstly, improper control when purchasing raw material from the suppliers. Actually, it is need to ensure the raw material comply to the incoming material specifications [17]. Besides that, a lab test will be conducted on certain material like rubber and color of materials.

Secondly, this company never simply change the supplier. If inconsistent of supplier, the elements can affect the characteristics of a compound. Hence, the rubber product's quality will be affected.

\section{Recommendation}

Base on the analysis that had been carried out, researcher had recognized the three main factors that influence quality inspection in the production process which are incompetence of men power, low performance of machines and wrong mixing compounds of materials. Therefore, researcher did gave some suggestions towards the Rubber Leisure Pte. Ltd.. based on the three factors.

\subsection{Improvement of men's performance}

A competence, knowledgeable and skilled men power is important to a manufacturing company [6]. By improve the competency of workers, it can help the company to 
increase its productivity and greater revenue. Actually, it can be done by coaching and mentoring the workers [4].

It is an on-going process designed to help the employee gain greater competence and overcome obstacles to improve performance. Through coaching, it can prepare employees for advancement and additional responsibility [8]. It can be done by identify the performance problem, setting a goal or objective and develop a performance improvement plan to let the employees follow [18]. Supervisor will need to concern the worker's performance and give the feedback towards them. Two way communication is an effective one way to determine both positive and negative performance efforts. In addition, it can help motivate the workers through the consistent guidance and boost their work performance [19].

\subsection{Prevention of low performance machines}

Machinery performance is the key factor that always overlooked by the management and this can cause looses which reduce the yield. Improper maintenance or low service will result in low standard of products. Therefore, a teamwork maintenance with engineering and production can be formed to fix machinery problems more regularly and precisely. It is advisable to put a group of knowledgeable and skilled engineers together in which each member know various things about the machines and processes. Hence, they able solve the problems immediately and prevent the machine from downtime [20].

Furthermore, if there is error occurred during production process, the machine shall be stop immediately and check the machine's condition. It is to prevent greater loss in revenue. Therefore, it is necessary to reduce machine's operating hours since it has certain life span limits [21].

\subsection{Prevention of low quality material}

Base on the research and analysis, it is being proved that mixing wrong compound is the major problem that influence the quality of rubber products. It is important to check the incoming raw materials at the first place. Raw material shall be stored in the correct storage conditions either in normal temperature or cold storage area [1].

When comes to the mixing compound, the raw materials have to be checked to ensure no changes have occurred during storage [22]. Then, all ingredients have to be weighed with high accuracy according to the types of products and then mixed together according to specified process parameters like temperature, timer and pressure. The mixing compound process is the most sensitive part, so extra concentration and careful need to put into it. If mistake is made here, it is too late to correct it later on.

\section{Conclusion}

As a conclusion, this research is being done to give a clear illustration regarding the factors that influence quality inspection during production process [3] in the rubber manufacturing industry. This research able to help the relevant companies to determine the root causes of influencing in-process quality inspection especially Rubber Leisure Pte. Ltd.. Then, the suitable solutions being recommended to improve the quality inspection standard in the production process [16]. Overall, researcher hope that this research paper able to give advantage to the rubber manufacturing industry to improve quality inspection standard through discover the root causes of influencing inspection standard and solve the problems successfully [2].

\section{Acknowledgement}

The researchers sincerely have been appreciating and gratitude an invaluable pronounced to the Research, Innovation and Commercialization Centre of Universiti Tun Hussein Onn Malaysia under a research fund and the Registrar Department that provides for a sufficient time to enable the researchers were successfully attending to present this paper.

\section{References}

1. Anjoran, R.. 15 Ways to Avoid Problems With Your Suppliers (2011)

2. Vivek, N. Quality Management System Handbook for Product Development Companies (pp. 1-22). New York: CRC Press (2005)

3. Hessel Schuurman. Quality Management and Competitiveness The Diffusion of The ISO 9000 Standards in Latin America and Recommendations for Government Strategies (1977)

4. Kao, T. Human factors in quality inspection process. $1-5(2003)$

5. Davis S. B. G. D.. Introduction to Total Quality Management for Production, Processing, and Services (3rd ed.). United States: Prentice Hall (2000)

6. Wu, H. Y., Chuang, C. L., Kung, Y. S., \& Lin, R. H.. Determination of optimal inspection sequence within misclassification error bound. Expert Systems with Applications, 38(5), 5366-5372 (2011)

7. Vienna. The Influence of The Workplace On Perceived Quality (2011)

8. Nzonzo, J. C. Training and Development Practices In An Organisation: An Intervention To Enhance Organisational Effectiveness, 2(4), 187-198 (2011)

9. Yu, H.-F., Yu, W. C., \& Wu, W. P. A mixed inspection policy for CSP-1 and precise inspection under inspection errors and return cost. Computers \& Industrial Engineering, 57(3), 652-659 (2009)

10. Kao, T. (2003). Human factors in quality inspection processes, 1-5 (2003)

11. Hessel Schuuman. Quality Management and competitiveness The Diffusion of The ISO 9000 Standards in Latin America and Recommendations for Government Strategies (1997) 
12. Dhillon, B. S., \& Liu, Y. Human error in maintenance: a review. Journal of Quality in Maintenance Engineering, 12(1), 21-36 (2006)

13. Su, L.-H., \& Tsai, H.-L. Flexible preventive maintenance planning for two parallel machines problem to minimize makespan. Journal of Quality in Maintenance Engineering, 16(3), 288-302 (2010)

14. Sondalini, M. 6 Ways to Improve Maintenance and Production, 1-5 (2002)

15. Shin, Sangman, Jung Tae Kim, and Yun Su Choi.. "Rubber Composition for Tire Tread and Tire Manufactured by Using the Same." U.S. Patent No. 20,150,299,436 (2015)

16. Besterfield, D. H. Quality Control . Eight Edit., pp. 77-109). New Jersey: Southern Illinois University (2009)

17. Vrat. Prem. "Material Specification, Codification, and Standardization."Materials Management. Springer India. 211-224 (2014)

18. Bamford, D. R., \& Greatbanks, R. W. The use of quality management tools and techniques: a study of application in everyday situations. International
Journal of Quality \& Reliability Management, 22(4), 376-392 (2005)

19. Henley, Amy J., et al. "Quantifying efficacy of workplace reinforcers: An application of behavioral economic demand to evaluate hypothetical work performance." Translational Issues in Psychological Science 2.2: 174 (2016)

20. Sultana, F., Science, C., Road, P., Razive, N. I., Tower, G., \& Azeem, A. Implementation of Statistical Process Control ( SPC ) For Production Data Control Chart Pareto Chart Pivot Chart Data Analysis Maintenance Communication Electrical Findings, $M(1)$, 15-21 (2009)

21. Way, F. Improve your machines and manufacturing processes: Milo, Christian, and Werner Grosch. "Changes in the odorants of boiled salmon and cod as affected by the storage of the raw material." Journal of Agricultural and Food Chemistry 44.8: 2366-2371 (2009)

22. Gu, Ben J., et al. "A quantitative method for measuring innate phagocytosis by human monocytes using real-time flow cytometry." Cytometry Part A 85.4: 313-321 (2014) 